\title{
Desgaste proteico energético en pacientes con diálisis peritoneal en México
}

\section{Protein-energy wasting on peritoneal dialysis patients in Mexico}

\author{
Dirigir la correspondencia a: \\ Francisco Yanowsky Escatell \\ Servicio de Nefrología, Hospital Civil de Guadalajara Dr. \\ Juan I Menchaca, \\ Salvador Quevedo y Zubieta \#750, Col. la Perla. \\ Guadalajara, Jalisco, México. \\ C.P. 44340, Guadalajara, Jalisco, México. \\ Tel: 3310083188 \\ Email: fyanowsky@hotmail.com
}

Francisco Yanowsky-Escatell (1) Leonardo Pazarín-Villaseñor (1) Jorge Andrade-Sierra (1) Miguel Zambrano-Velarde (1) Francisco Preciado-Figueroa (1) Christian Santana-Arciniega (2) Rogelio Galeno-Sánchez (2)

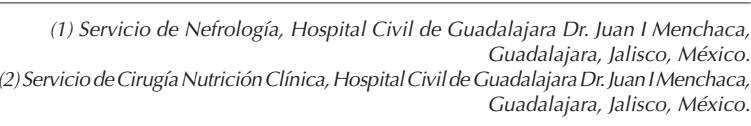

Este trabajo fue recibido el 28 de julio de 2016 y aceptado para ser publicado el 16 de Diciembre de 2016.

Sr. Editor:

México es uno de los países con mayor uso de diálisis peritoneal (DP) en el mundo. Los resultados de la DP (morbimortalidad, tasa de peritonitis y supervivencia de la técnica) en México son comparables a los de otros países (1).

El panel de expertos de la International Society of Renal Nutrition and Metabolism (ISRNM) propuso el término de "desgaste proteico energético" (DPE) como aquel estado que presenta un descenso tanto de los depósitos proteicos como de las reservas energéticas (esto es, una pérdida de músculo y de grasa) debido a las múltiples alteraciones nutricionales y catabólicas que ocurren en la enfermedad renal crónica2,3. Estas alteraciones incluyen: disminución en la ingestión calórico-proteica, condiciones co-mórbidas, trastornos endocrinos, aumento en la producción de citoquinas inflamatorias, toxinas urémicas, acidosis metabólica y pérdida de nutrientes durante la terapia de reemplazo renal, etc $(2,3)$.

El término DPE es el que mejor define los síndromes relacionados al desgaste muscular, malnutrición e inflamación que ocurren en esta condición. La caquexia ocurre con poca frecuencia en la enfermedad renal y es la forma más severa de DPE, ya que este último puede referirse a grados leves de depleción de masa proteica y energética2. Por este motivo, nos ha parecido oportuno exponer los datos recientes sobre el DPE en nuestro país, para así, implementar las estrategias adecuadas para abordarlo.

La prevalencia de DPE ha sido reportada en un amplio rango que va del 49-92\% en la población tanto prevalente (casos ya existentes en DP) como incidente (casos nuevos en DP) en los distintos programas de DP en México (tabla 1) (4-8). Los pacientes sin seguridad social son los que presentan mayor DPE $(5,7,8)$. Este es un grave problema debido a que el DPE se asocia con mortalidad en estos pacientes (9). 
Por lo tanto, las diferentes intervenciones disponibles actualmente por la ISRNM para la prevención y tratamiento de DPE deben ser empleadas. Asesoramiento nutricional continuo, optimizar la ingestión de nutrientes en la dieta y manejo de distintas comorbilidades (acidosis metabólica, inflamación, deficiencias hormonales, diabetes, resistencia a la insulina, etc) son las medidas preventivas. La modificación en la prescripción de DP no ha demostrado mejorar significativamente el estado nutricional en nuestra población. En pacientes en los que las medidas preventivas no son capaces de disminuir la pérdida de las reservas proteicas y energéticas, se deberá comenzar con suplementación nutricional, vía oral, intraperitoneal, enteral o parenteral. Los agentes anabólicos, estimulantes del apetito, intervenciones antiinflamatorias y ejercicio pueden ser utilizados como terapias adyuvantes (10).

Es de destacar que el DPE es altamente prevalente y varia en los distintos programas de DP en nuestro medio. Consideramos que las intervenciones propuestas por la ISRNM para la prevención y tratamiento de DPE deberán ser empleadas en nuestra población.

\section{TABLA 1}

Prevalencia de DPE en los distintos programas de DP en México.

Autor (año, referencia, estado)

n

DPE (\%)

Espinosa A y cols. (1996) (5) (Ciudad de México)

Garcia-Garcia G y cols (2003) (7) (Jalisco)

90 pacientes prevalentes

82

39 pacientes incidentes

92

61 pacientes prevalentes

73

Aguirre-Galindo BA y cols (2003) (4) (Coahuila)

100 pacientes prevalentes

49-50

Martín-Del-Campo F y cols. (2012) (6) (Jalisco)

73 pacientes prevalentes

81

Yanowsky-Escatell FG y cols. (2015) (8) (Jalisco)

69 pacientes incidentes

65

DPE: desgaste proteico energético; DP: diálisis peritoneal; n: número.

Conflicto de interés: Los autores declaran no tener ningún conflicto de intereses.

\section{BIBLIOGRAFÍA}

1. Cueto-Manzano AM, Rojas-Campos E. Status of renal replacement therapy and peritoneal dialysis in Mexico. Perit Dial Int. 2007; 27(2):142-8.

2. Fouque D, Kalantar-Zadeh K, Kopple J, Cano N, Chauveau O, Cuppari L, y cols. A proposed nomenclature and diagnostic criteria for protein-energy wasting in acute and chronic kidney disease. Kidney Int. 2008; 73:391-8.

3. Carrero JJ, Stenvinkel P, Cuppari L, Ikizler TA, Kalantar-Zadeh K, Kaysen G, y cols. Etiology of the protein-energy wasting syndrome in chronic kidney disease: A consensus statement from the International Society of Renal Nutrition and Metabolism (ISRNM). J Ren Nutr. 2013; 23(2):77-90.

4. Aguirre-Galindo BA, Prieto-Fierro JG, Cano P, Abularach L, Nieves-Renteria A, Navarro M, y cols. Effect of polymerics diets in patients on continuous ambulatory peritoneal dialysis. Perit Dial Int. 2003; 23(5):434-9.

5. Espinosa A, Cueto-Manzano AM, Velazquez-Alva C, Hernandez A, Cruz N, Zamora B, y cols. Prevalence of malnutrition in Mexican CAPD diabetic and non-diabetic patients. Adv Perit Dial. 1996; 12:302-6.

6. Martín-Del-Campo F, Batis-Ruvalcaba C, Gonzáles-Espinosa L, Rojas-Campos E, Ángel JR, Ruiz N, y cols. Dietary micronutrient intake in peritoneal dialysis patients: relationship with nutrition and inflammation status. Perit Dial Int. 2012; 32(2):183-91.

7. Garcia-Garcia G, Nuñez-Martinez MG, Obrador GT. Prevalence of malnutrition in low-income Mexican CAPD patients. Perit Dial Int. 2003; 23(5):501-4.

8. Yanowsky-Escatell FG, Pazarín-Villaseñor L, Andrade-Sierra J, Zambrano-Velarde MA, Preciado-Figueroa FM, SantanaArciniega CJ, y cols. Association of serum albumin and subjective global assessment on incident peritoneal dialysis patients. Nutr Hosp. 2015; 32(6):2887-92.

9. Leinig CE, Moraes $T$, Ribeiro S, Riella MC, Olandoski M, Martins $C, y$ cols. Predictive value of malnutrition markers for mortality in peritoneal dialysis patients. J Ren Nutr. 2011; 21(2):176-83.

10. Ikizler TA, Cano NJ, Franch H, Fouque D, Himmelfarb J, Kalantar-Zadeh $K, y$ cols. Prevention and treatment of protein energy wasting in chronic kidney disease patients: a consensus statement by the International Society of Renal Nutrition and Metabolism. Kidney Int. 2013; 84:1096-107. 